\title{
Fluidized Bed Chemical Vapor Deposition of Zirconium Nitride Films
}

Dennis D. Keiser, Jr, Delia Perez-Nunez, Sean M. McDeavitt, Marie Y. Arrieta

July 2017

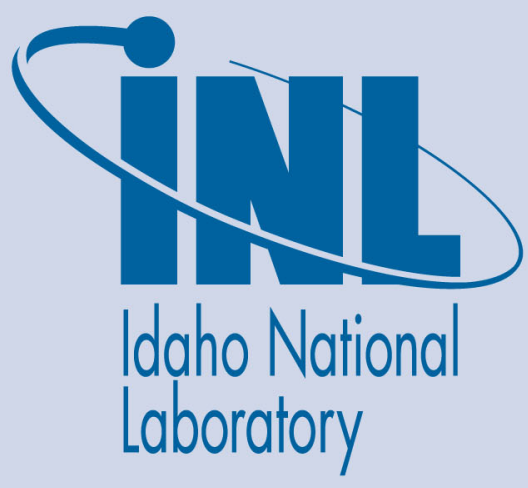

The INL is a U.S. Department of Energy National Laboratory operated by Battelle Energy Alliance 


\section{Fluidized Bed Chemical Vapor Deposition of Zirconium Nitride Films}

Dennis D. Keiser, Jr, Delia Perez-Nunez, Sean M. McDeavitt, Marie Y. Arrieta

July 2017

Idaho National Laboratory Idaho Falls, Idaho 83415

http://www.inl.gov

Prepared for the

U.S. Department of Energy

Under DOE Idaho Operations Office

Contract DE-AC07-05ID14517 


\title{
Fluidized Bed Chemical Vapor Deposition of Zirconium Nitride Films
}

\author{
Marie Y. Arrieta, ${ }^{a}$ Dennis D. Keiser Jr., ${ }^{b}$ Delia Perez-Nunez, ${ }^{{ }^{*}} *$ and Sean M. McDeavitt ${ }^{\mathrm{c}}$ \\ ${ }^{a}$ Sandia National Laboratories, Albuquerque, New Mexico 87185 \\ ${ }^{b}$ Idaho National Laboratory, Idaho Falls, Idaho 83401 \\ ${ }^{c}$ Texas A\&M University, Department of Nuclear Engineering, College Station, Texas 77840
}

Received November 11, 2016

Accepted for Publication May 23, 2017

\begin{abstract}
A fluidized bed-chemical vapor deposition (FB-CVD) process was designed and established in a two-part experiment to produce zirconium nitride barrier coatings on uranium-molybdenum particles for a reduced enrichment dispersion fuel concept. A hot-wall, inverted fluidized bed reaction vessel was developed for this process, and coatings were produced from thermal decomposition of the metallo-organic precursor tetrakis(dimethylamino)zirconium (TDMAZ) in highpurity argon gas. Experiments were executed at atmospheric pressure and low substrate temperatures (i.e., 500 to $550 \mathrm{~K}$ ). Deposited coatings were characterized using scanning electron microscopy, energy dispersive spectroscopy, and wavelength dis-persive spectroscopy. Successful depositions were produced on $1 \mathrm{~mm}$ diameter tungsten wires and fluidized $\mathrm{ZrO}_{2}-\mathrm{SiO}_{2}$ microspheres (185 to $250 \mu \mathrm{m}$ diameter) with coating thicknesses ranging from 0.5 to $30 \mu \mathrm{m}$. The coating deposition rate was nominally estimated to be $0.04 \pm 0.02 \mu \mathrm{m} / \mathrm{h}$. The ZrN coating adhered to the microspheres, but there was a significant oxygen and possible carbon contamination.
\end{abstract}

Keywords - FB-CVD, ZrN coatings, uranium-molybdenum particles.

Note - Some figures may be in color only in the electronic version.

\section{INTRODUCTION}

The Material Management and Minimization (M3) Program, previously called the Reduced Enrichment for Research and Reactor Program, was established in 1978 by the U.S. Department of Energy with the primary objective to reduce and eventually eliminate the use of highenrichment uranium (HEU) in research and test reactors worldwide. ${ }^{1}$ A major goal of the M3 program was to develop advanced low-enrichment-uranium (LEU) fuels to replace the HEU in research reactors while maintaining experimental performance, economic, and safety aspects of the reactors. ${ }^{2}$ Over 40 research reactors have been converted to date through this program; however, there are still reactors in operation whose high flux requirements cannot be met by currently developed LEU fuel.

*E-mail: deperez@tamu.edu
One fuel concept under development for this application consists of the dispersion of uranium-molybdenum (U-Mo) microspheres within an aluminum matrix. ${ }^{3}$ Extensive testing of U-Mo dispersion fuels ${ }^{4,5}$ revealed interactions between the U-Mo fuel and the $\mathrm{Al}$ matrix during irradiation. Neutron radiation-enhanced interdiffusion resulted in fuel plate pillowing and eventually plate failure. ${ }^{4-7}$ While fuel performance is a multifaceted challenge with many performance-limiting phenomena, such as fission gas swelling and mechanical property changes, the emphasis of this work was on the development of a process to create a diffusion barrier between the alloy fuel particles and the aluminum matrix. The insertion of zirconium nitride $(\mathrm{ZrN})$ as an inert diffusion barrier between the fuel particles and the aluminum matrix has been proposed as one option to mitigate these interactions. ${ }^{4}$

The application of this barrier requires a deposition method that is amenable to coating powder surfaces of 
the U-Mo microspheres (nominally 70 to $150 \mu \mathrm{m}$ in diameter) before its incorporation into the dispersion fuel plate matrix. Among the various methods, fluidized bed-chemical vapor deposition (FB-CVD) is effective for powder applications as nucleation and growth of the coating layer occurs on every available surface. ${ }^{8,9}$

The precursor selected for the CVD process must be chemically compatible with the substrate, and the required process temperature cannot be thermally damaging to the fuel. One common CVD precursor used for $\mathrm{ZrN}$ deposition is zirconium tetrachloride ${ }^{10}\left(\mathrm{ZrCl}_{4}\right)$, but this compound was rejected because of the parasitic formation of uranium chlorides and the potential for the requisite processing temperatures to exceed the U-xMo liquidus temperature near $\sim 1475 \mathrm{~K}$ (Ref. 11). Therefore, metallo-organic precursors that deposit $\mathrm{ZrN}$ via thermal decomposition were sought. The low binding energy in the metallo-organic molecules reduces the required substrate temperature to initiate the chemical reaction ${ }^{12-14}$ and is therefore suitable for the coating process for the U-Mo fuel particles. The metallo-organic precursor chosen for the ZrN FB-CVD process was tetrakis-(dimethylamino) zirconium $\left(\mathrm{Zr}\left[\mathrm{N}\left(\mathrm{CH}_{3}\right)_{2}\right]_{4}\right)$ (TDMAZ), which belongs to the alkyl subset of metallo-organic precursors and begins to decompose at $473 \mathrm{~K}\left(200^{\circ} \mathrm{C}\right)$ (Ref. 14).

A $\mathrm{ZrN}$ coating was selected as a candidate barrier for U-Mo particles dispersed in an aluminum matrix because it is chemically inert to the component materials and exhibits favorable diffusivity and thermal properties. In addition, low-temperature, low-pressure systems typically produce fine-grained structure deposits.

Several coating experiments using different powders of varied density and sphericity were used to test and refine the fluidization process within the FB-CVD reactor, thus avoiding experimental and safety complications associated with radioactive materials. Spherical zirconiasilica $\left(\mathrm{ZrO}_{2}-\mathrm{SiO}_{2}\right)$ microspheres, readily available in the Fuel Cycle and Materials Laboratory, were used as a surrogate for U-Mo powder to be coated with $\mathrm{ZrN}$.

The focus of this work was to design and demonstrate the performance of a FB-CVD system capable of fluidizing powder substrates of varied sizes and of producing uniform $\mathrm{ZrN}$ coatings with thicknesses on the order of 1 to $5 \mu \mathrm{m}$ on U-Mo microspheres.

\section{EXPERIMENTAL}

\section{II.A. Materials}

The metallo-organic precursor chosen for the $\mathrm{ZrN}$ FB-CVD process was TDMAZ. The TDMAZ crystals
(>99.99\%) (STREM Chemicals Incorporated, Newburyport, Massachusetts) are a white/yellow crystalline material at room temperature with a melting point of $331 \mathrm{~K}$ $\left(58^{\circ} \mathrm{C}\right)$ (Refs. 15 and 16). The carrier gas for these experiments was high-purity argon (99.99\%). There is no documentation in the literature regarding the use of the TDMAZ precursor in atmospheric pressure CVD, and the vapor pressure and gravimetric analyses were not readily available ${ }^{16}$; however, research performed using low-pressure, plasmaactivated CVD indicated that thin films were deposited using TDMAZ with substrate temperatures as low as $150^{\circ} \mathrm{C}$ and as high as $500^{\circ} \mathrm{C}$; the subsequent films characterized were composed of zirconium, nitrogen, carbon, and oxygen. $^{15,17,18}$

\section{II.B. FB-CVD System}

The FB-CVD experimental setup, shown in Fig. 1, consisted of an inert carrier gas delivery line, a precursor delivery system, a particle trap, and a fluidized bed reaction vessel. Individual components of the system are described elsewhere. ${ }^{19}$

The U-Mo powder consisted of particles ranging in size; smaller particles would overfluidize out of the system into the particle trap, and larger particles would drop from the vessel into the particle catch below. Additionally, as coatings would grow on the powder substrate, the particles would grow heavier and fall from the fluidized bed. To address these issues, a new type of reaction vessel, an inverted fluidized bed, was developed and is schematically pictured in Fig. 2.

The top half of the reaction vessel is made from an aluminum section welded to a $2.540 \mathrm{~cm}$ Swagelok UltraTorr vacuum fitting and a $0.635 \mathrm{~cm}$ stainless steel gas inlet/outlet line. A $2.540 \mathrm{~cm}$ outer diameter (OD) Pyrex glass tube, $30.500 \mathrm{~cm}$ in length, is used as the reaction vessel and particle containment vessel and is secured to the aluminum housing with an Ultra-Torr vacuum fitting and a high-temperature silicon O-ring. All gas lines leading to and from the vessel were sealed with the Swagelok ball valves. A rotary vane vacuum pump was attached to the end of the exhaust system to facilitate fluidization within the vessel. The vessel is loaded with the particulate substrate inside an inert atmosphere glove box by unscrewing the Ultra-Torr fitting that clamps the O-ring to the glass tube. The glass tube then slides out of the aluminum housing for loading/unloading or cleaning purposes.

The gas inlet consists of two tubes: a $0.952 \mathrm{~cm}$ OD stainless steel tube and a second $0.317 \mathrm{~cm}$ OD stainless steel tube placed inside the first. The first tube carries the 


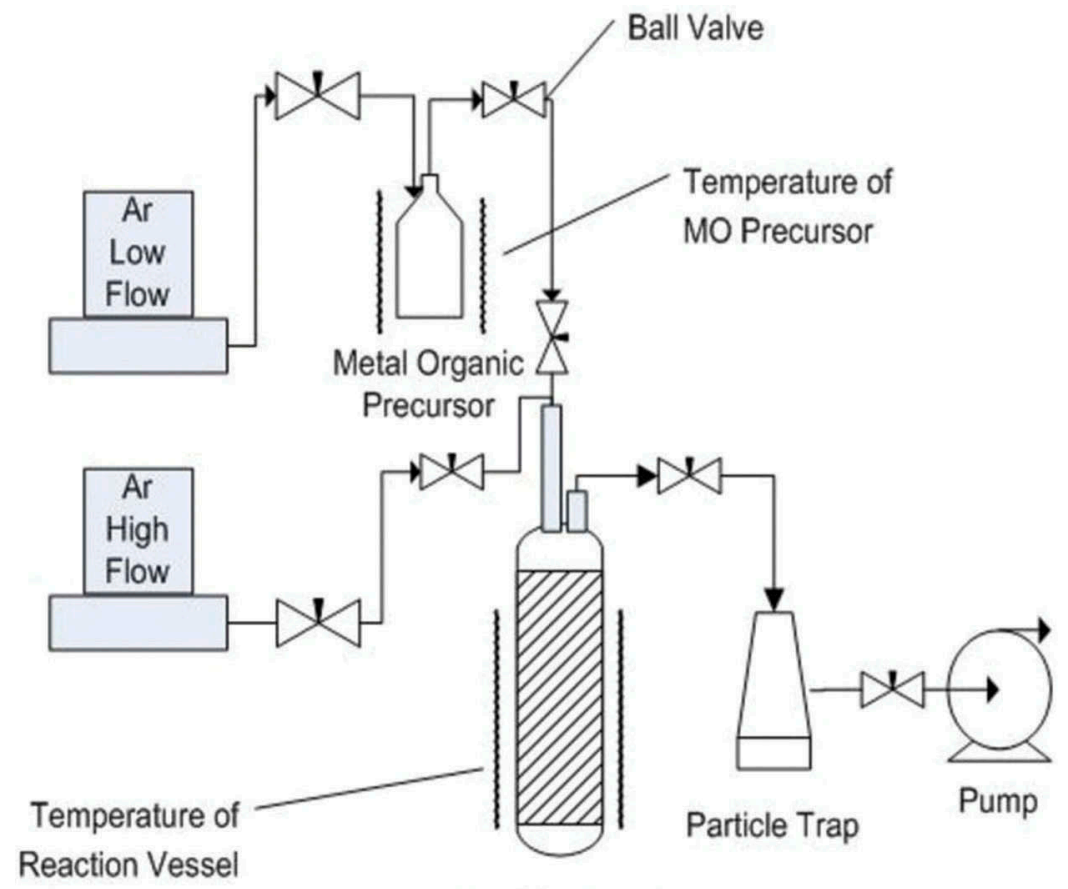

Reaction Vessel

Fig. 1. Diagram of the FB-CVD system.

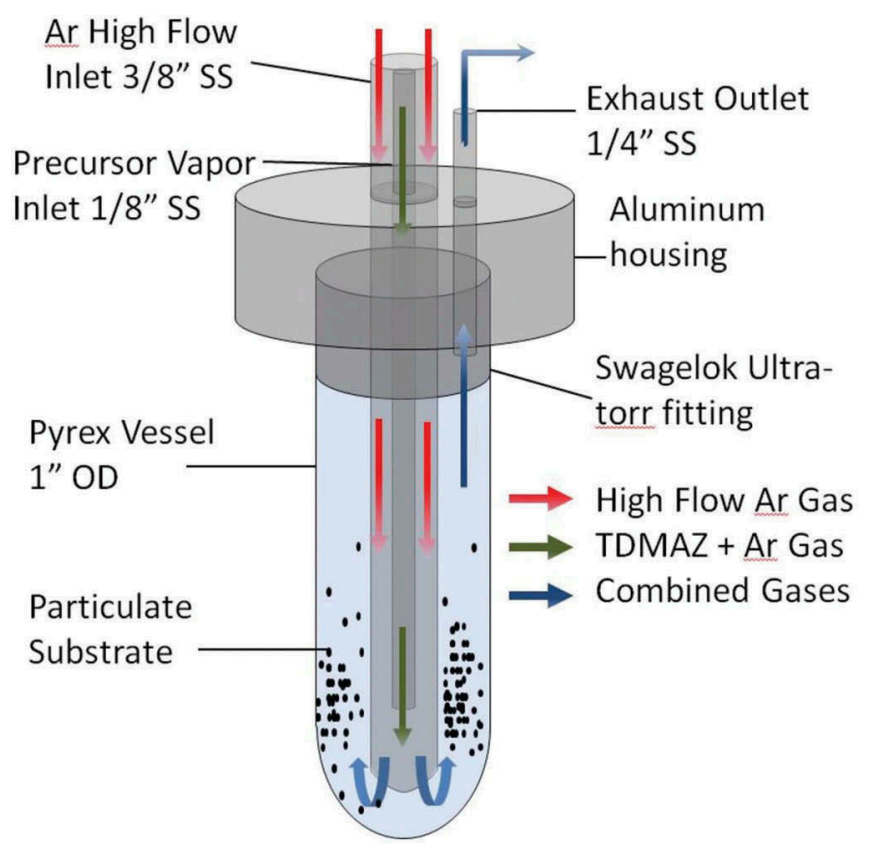

Fig. 2. Schematic of the inverted fluidized bed reaction vessel (not to scale).

fluidization argon gas, and the second carries the TDMAZ precursor vapor and argon carrier gas. The two gas streams are delivered in the hot zone at the bottom of the reaction vessel at different flow rates: a high-flow gas corresponding to the fluidization gas and a lower-flow gas to deliver the precursor. The gas flow is reversed at the bottom of the tube, and the redirected flow fluidizes the microspheres around the stainless steel lines. This approach allows for an efficient dilution of the precursor over a fast-moving circulation of the microspheres. The exhaust gas exits through the $0.635 \mathrm{~cm}$ stainless steel tube on the top of the reaction vessel.

The reaction vessel was placed inside a moveable aluminum metal annulus that was heated externally with high-temperature fiberglass heater tape (Omega model DHT051040LD) and then surrounded by insulation. Type-K thermocouples (Omega KQXL-116G-12) connected to a temperature data logger (Omega OM-CP-OCTTEMP2000-CERT) were used to monitor the temperatures of the top, center, and bottom of the annulus as well as the inside of the reaction vessel to verify temperature uniformity inside and along the length of the heated portion of the vessel. The temperature of the furnace was set to $425^{\circ} \mathrm{C}$, but the temperature was found to fluctuate from the setpoint over a range of $\pm 5^{\circ} \mathrm{C}$ and over the length of the furnace $\pm 7.5^{\circ} \mathrm{C}$.

The bottom $15.250 \mathrm{~cm}$ of the $30.500 \mathrm{~cm}$ reaction vessel was heated, which prevented the precursor from heating up too rapidly while traversing the length of the gas inlet to the bottom of the reaction vessel. The annulus could slide up the length of the vessel, exposing the fluidized bed at the bottom, enabling periodic fluidization checks during system 
operation. The temperature of the heater tape was controlled with a variable autotransformer (Staco Energy model 3PN1010B).

The argon supply was divided between two mass flow controllers: a high-flow mass flow controller (Omega model FMA5524) to provide the fluidization gas and a low-flow mass flow controller (Omega model FMA5508) to provide the carrier gas for the TDMAZ precursor. The high-flow line entered the reactor from the bottom inlet. The low-flow argon line is passed through the heated precursor bubbler to carry the precursor vapor to the inlet line for the reaction vessel.

The particulate substrate was loaded into the reaction vessel in the inert atmosphere glove box, sealed, and then transferred to the FB-CVD system assembly. The system was heated and purged with argon gas for $3 \mathrm{~h}$ prior to each experimental run to displace air and moisture. The precursor bubbler was loaded with TDMAZ crystals in the inert atmosphere glove box, sealed, and transferred to the system assembly where it was heated to a predetermined temperature. The precursor bubbler bypass valve was closed, and the TDMAZ precursor line valve was opened to the reaction vessel. At the conclusion of the experiment, the bubbler valves were closed, and the heater tape and heater cartridge were shut down, while the argon continued to flow through the vessel, purging any remaining precursor vapor from the system. The valves on the top of the vessel were closed, sealing the coated particles inside. The vessel was removed from the system and transferred to an inert atmosphere glove box.

Table I shows the experiments that were completed using the inverted fluidized bed reactor using argon gas and the TDMAZ precursor. These experiments used the $\mathrm{ZrO}_{2}-\mathrm{SiO}_{2}$ microspheres (185 to $250 \mu \mathrm{m}$ ) and a tungsten wire as substrates for the coating process.

Samples collected from each experiment were photographed using an optical microscope. Samples were then prepared and taken to the electron microprobe where they were characterized with wavelength dispersive spectroscopy, energy dispersive spectroscopy, and backscatter electron imaging (BSE) using a four-spectrometer electron probe microanalyzer (Cameca model SX50) equipped with a Princeton Gamma-Tech energy dispersive system and a dedicated Sun workstation used for image analysis. $^{20}$

\section{RESULTS}

Successful coating via FB-CVD requires maintaining a fully expanded fluidized bed over the course of the experiment. The inverted vessel design successfully fluidized particles of various sizes and densities without losses at the particle trap.

The coating experiments were performed on the following substrates: $1 \mathrm{~mm}$ OD tungsten wire, $300 \mathrm{~mm}$ in length, and $\mathrm{ZrO}_{2}-\mathrm{SiO}_{2}$ microspheres (185 to $250 \mu \mathrm{m}$ ). The length was chosen so that the wire would start at the bottom of the coated particle trap and extend out the top outlet of the reaction vessel. The wire would not move since it was stabilized at the bottom of the particle trap and the location within the vessel.

Substrate temperature was used as the principal process variable. The TDMAZ was delivered to the reaction vessel in argon gas at 1 atm pressure, and substrate temperatures ranged from approximately $500 \mathrm{~K}$ to $550 \mathrm{~K}\left(230^{\circ} \mathrm{C}\right.$ to $\left.275^{\circ} \mathrm{C}\right)$.

The $\mathrm{ZrO}_{2}-\mathrm{SiO}_{2}$ particles fluidized at a high argon flow rate of $1.0 \pm 0.5 \mathrm{~L} / \mathrm{min}$ and a low argon flow rate of $95 \pm 2 \mathrm{~mL} / \mathrm{min}$, when the bed of particles became fully expanded (Fig. 3). These two flow rates were used for all the experiments completed with the FB-CVD system.

The use of the solid TDMAZ precursor at atmospheric pressure proved challenging over the course of this research. The vapor pressure of the TDMAZ was too low to obtain a reliable vaporization rate or partial pressure calculation of the precursor. The fluidized bed experiments were all open system processes, and the

TABLE I

Inverted Fluidized Bed Experiments

\begin{tabular}{|c|l|l|c|c|c|}
\hline Test Number & Vessel & Substrate & Heater Temperature $\left({ }^{\circ} \mathrm{C}\right)$ & Precursor $(\mathrm{g})$ & Coating Observed \\
\hline 4.4 .1 & II: Inverted & Zirconia-silica & $237 \pm 5$ & 1.9 & Yes \\
4.4 .2 & II: Inverted & Zirconia-silica & $250 \pm 5$ & 3.01 & Yes \\
4.4 .3 & II: Inverted & Zirconia-silica & $265 \pm 5$ & 3.5 & Yes \\
$4.4 .4 \mathrm{a}$ & II: Inverted & Zirconia-silica & $255 \pm 5$ & -12 & Yes \\
$4.4 .4 \mathrm{~b}$ & II: Inverted & Zirconia-silica & $210 \pm 5$ & 5.52 & No \\
4.4 .5 & II: Inverted & Zirconia-silica/W wire & $280 \pm 5$ & & Yes \\
\hline
\end{tabular}




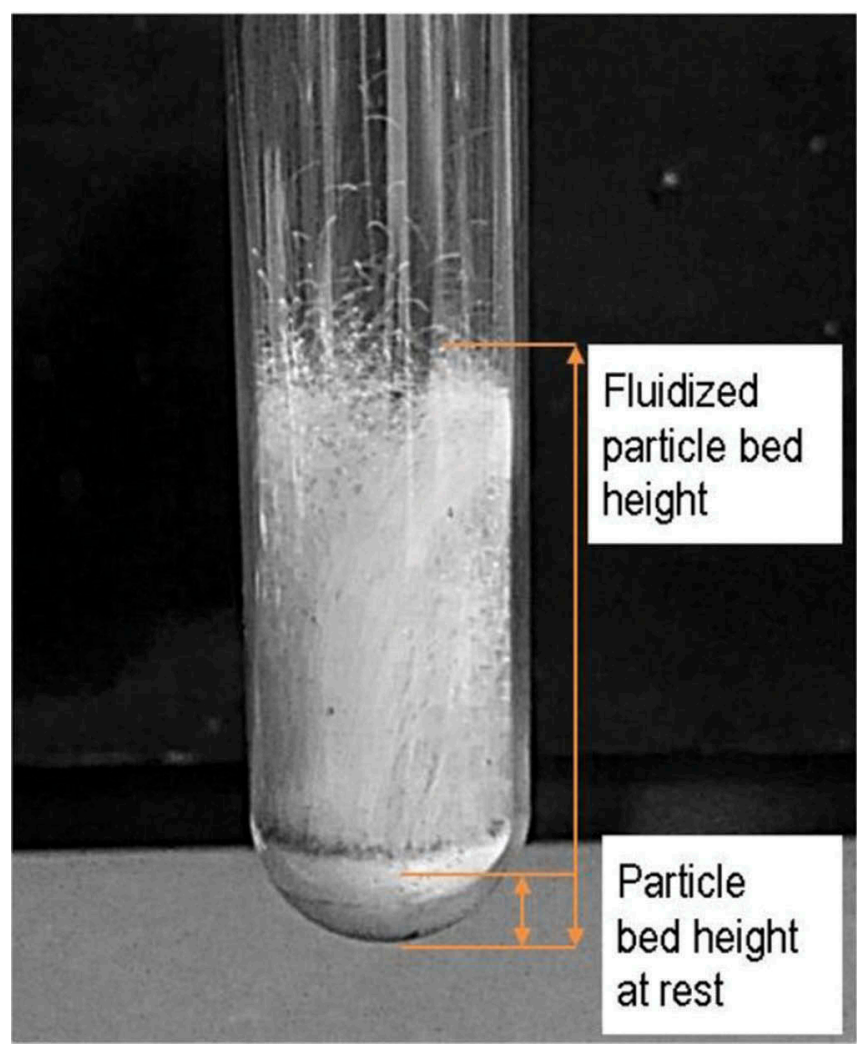

Fig. 3. Fluidization of $\mathrm{ZrO}_{2}-\mathrm{SiO}_{2}$ particles in the inverted fluidized bed system; the relative heights of the static bed and fully expanded bed are indicated in the picture.

system pressure could not be reduced to increase the vaporization of the precursor. Heating the precursor above the melting point $\left(60^{\circ} \mathrm{C}\right)$ appeared to reduce the vaporization rate of the precursor over time, indicating that possible decomposition reactions ${ }^{21}$ were occurring during heating, changing the nature of the precursor. The method used to overcome this negative effect was to heat the precursor below the melting point of the crystals $\left(52^{\circ} \mathrm{C}\right)$ to slow the decomposition process but still increase the vaporization rate.

The experiments began with a deposition time of $4 \mathrm{~h}$ that was then increased to a deposition time of $69 \mathrm{~h}$ as the coating rate was limited by the vapor delivery of the TDMAZ precursor. BSE images of the microsphere surface from select experiments are provided in Fig. 4. The maps show the coating progression with increased deposition time. The final experiment was run for a total of $69 \mathrm{~h}$ at a temperature of $275^{\circ} \mathrm{C}$ at atmospheric pressure using the $\mathrm{ZrO}_{2}-\mathrm{SiO}_{2}$ microspheres and the tungsten wire. An assumption with the FB-CVD experiments is that film deposition occurs equally on all fluidized substrates within the heated zone of the reaction vessel. To verify uniform coating deposition, the bottom $15.250 \mathrm{~cm}$ of the reaction vessel tube used in the final experiment was sectioned and analyzed with the coated substrates (Fig. 7).

\section{III.A. Microprobe Characterization}

The uncoated spheres were examined and compared to the coated spheres produced from three experiments (Fig. 4). The uncoated $\mathrm{ZrO}_{2}-\mathrm{SiO}_{2}$ microspheres appeared to have a heterogeneous surface with various compositions of zirconium, silicon, and oxygen.

The coating on the surface of the tungsten wire (Fig. 5) appears more homogenous than that of the $\mathrm{ZrO}_{2}-\mathrm{SiO}_{2}$ microspheres.

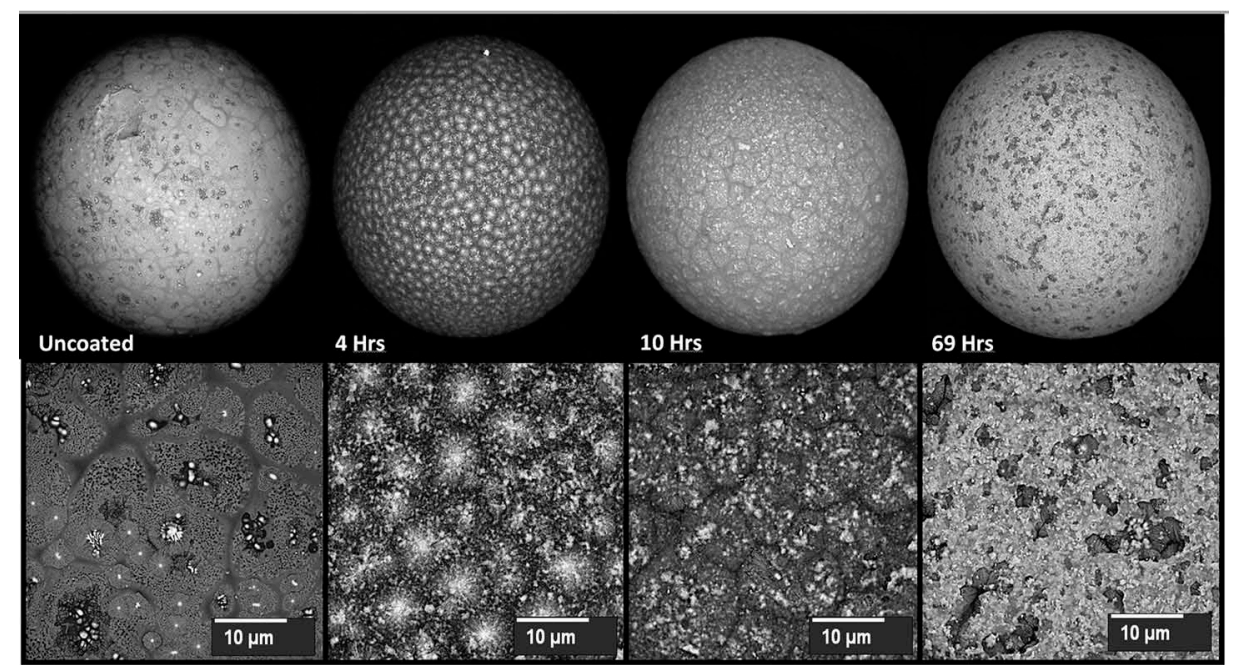

Fig. 4. Coating progression on $\sim 200 \mu \mathrm{m}$ microspheres with increased deposition time coupled with the corresponding $40 \times 40 \mu \mathrm{m}$ image of the surface area below. Uncoated microsphere (far left) with increasing deposition time toward the right. 


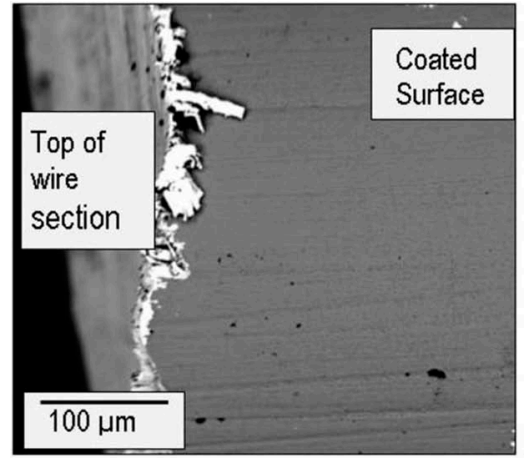

(a)

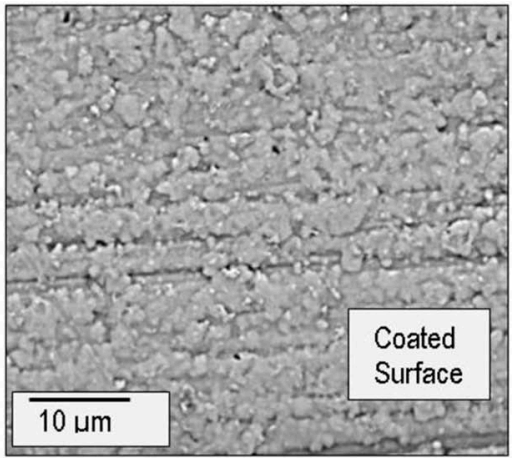

(b)

Fig. 5. (a) BSE image of the top of the sectioned coated tungsten wire and (b) a magnified image of the coated surface.

The coating varied from $0.5 \mu \mathrm{m}$ up to $30 \mu \mathrm{m}$ around the circumference of the wire. This was attributed to the placement of the stationary wire next to the gas inlet at the bottom of the reaction vessel. The magnified image of the coating displays a layered appearance; the cause of the layers is currently unknown. The gap between the wire and the coating is from where the epoxy pulled the coating from the wire as it hardened (Fig. 6).

The BSE image analysis of the reaction vessel circumference cross section displayed an even, unvarying coating of roughly $2.5 \mu \mathrm{m}$ around the inner circumference of the reaction vessel (Fig. 7), validating that the

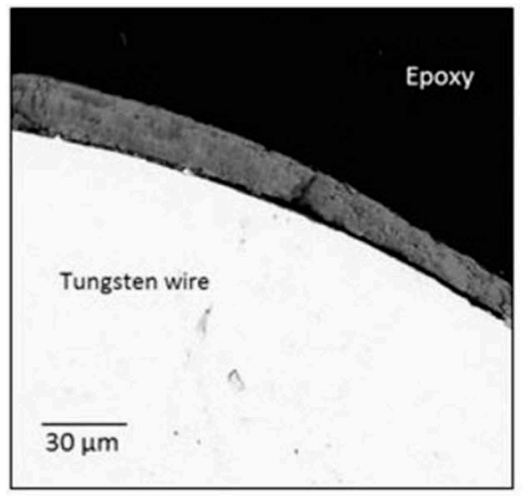

(a)

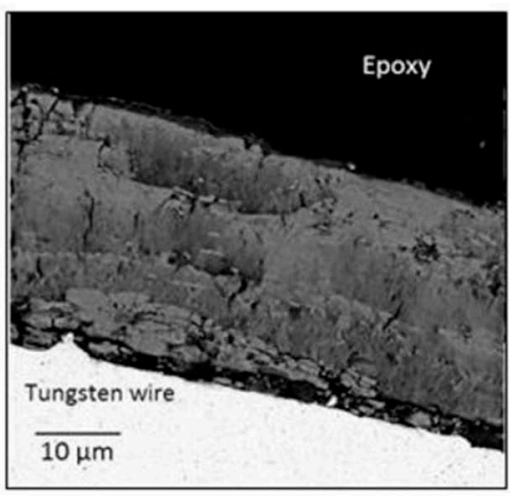

(b)

Fig. 6. (a) BSE image of a cross section of the tungsten wire and (b) a magnified image of the coating.

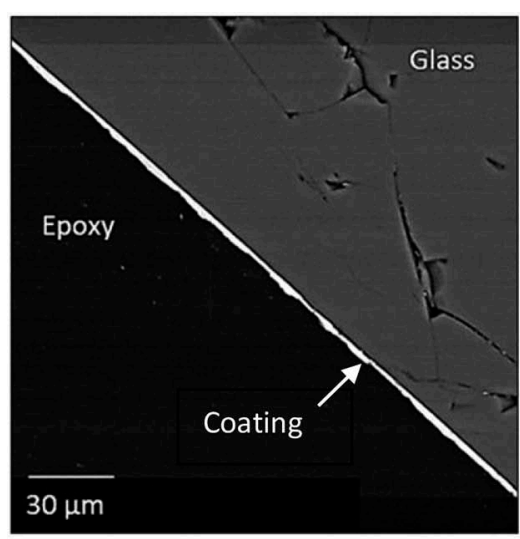

(a)

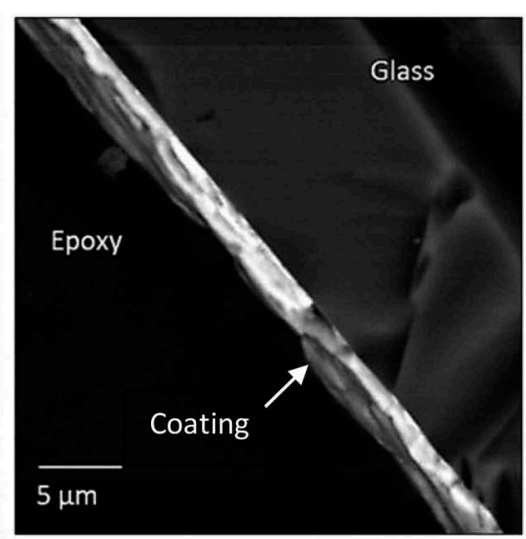

(b)

Fig. 7. (a) BSE image of the cross-sectional area of the glass reaction vessel and (b) a magnified image of the inner coated surface. 
thin film deposited equally within the heated zone $(15.25 \mathrm{~cm}$ in length) of the vessel.

\section{DISCUSSION}

\section{IV.A. CVD Results}

The inverted FB-CVD system achieved thin zirconium-bearing coatings on the substrates used in each of the experiments. The character of coatings varied depending on the substrate used. The coatings produced on the $\mathrm{ZrO}_{2}-\mathrm{SiO}_{2}$ microspheres were varied in thickness across the sphere surface, while the coatings produced on the reaction vessel had a uniform thickness across the surface. The coating on the reaction vessel achieved after $69 \mathrm{~h}$ of system operation time was roughly $2.5 \mu \mathrm{m}$ in thickness and appeared uniform across the vessel surface. Assuming a constant precursor delivery to the substrate surface, this would equal a coating deposition rate of $0.04 \pm 0.02 \mu \mathrm{m} / \mathrm{h}$. This coating rate is significantly lower than deposition rates of up to $0.76 \mu \mathrm{m} / \mathrm{h}$ reported by Kim et al. ${ }^{15}$

\section{IV.B. Coating Impurities}

Zirconium has a high affinity for oxygen. The formation of an oxide layer in the film is expected even in a vacuum environment $\left(10^{-4} \mathrm{~Pa}\right)$ (Ref. 14). The oxygen impurities in the system can be attributed to oxygen absorbed on the inside of the reaction vessel surface, oxygen present in the process gases, or possible leaks in the experimental system.

Research with metallo-organic precursors for zirconium and titanium depostion indicate that carbon impurities should be expected. The ligands directly bound to the $\mathrm{ZrN}$ molecule may not completely separate from the molecule during the chemisorption reaction on the substrate surface, which can then be incorporated into the growing film. Decomposition reactions occurring prior to or during the deposition process could also lead to the carbon atoms directly binding to the zirconium metal atom ( $\mathrm{ZrC})$ adding further impurities to the coating. $^{12,15,22}$

Ammonia can be introduced into the CVD system to reduce the carbon impurities through a series of transamination reactions. ${ }^{18}$ The process is described by Fix et al. in the following equation, which is Eq. (9) in Ref. 18:

$$
\mathrm{N}\left(\mathrm{NR}_{2}\right)_{4}+\mathrm{NH}_{3} \rightarrow \mathrm{M}\left(\mathrm{NR}_{2}\right)_{4}-\mathrm{n}\left(\mathrm{NH}_{2}\right) \mathrm{n}+\mathrm{nHNR}_{2},
$$

where for the case of the TDMAZ precursor, $\mathrm{R}=\mathrm{CH}_{3}$ and $\mathrm{M}=\mathrm{Zr}$. However, ammonia can react with the TDMAZ precursor to form a powder even at low temperatures, ${ }^{18}$ and the coating process would need to be adjusted to avoid parasitic reactions within the chamber.

The metallo-organic CVD experiment in literature $^{15}$ is operated at lower temperatures since the substrate is within an ultra-low-pressure environment. In the atmospheric pressure system, a temperature increase will increase the coating deposition rate ${ }^{14}$ and will decrease the carbon contamination found in thin film deposition processes utilizing the metallo-organic precursors. ${ }^{11,14,18}$ This process will need to be optimized as the coating rate competes with parasitic gas phase reactions, which are more probable with higher temperatures. ${ }^{14}$

\section{CONCLUSION}

A new fluidized bed vessel capable of fluidizing particulate substrates of varied size and density was conceived and developed. The FB-CVD system utilizing a metallo-organic precursor at low deposition temperatures and atmospheric pressure was successfully designed and developed to fluidize and coat particulate substrates with zirconium-based coatings. Process variables were defined, and the deposition of thin zirconium-bearing barrier coatings has been demonstrated. The use of TDMAZ precursor was challenging due to the narrow window of operating temperatures and the strong tendency to oxidize during operation. However, the system was functional, and precursor delivery was readily achieved. Further work is needed to improve the chemical behavior of the FB-CVD system and reduce contamination in the final coating and to fully characterize the coatings.

\section{ORCID}

Delia Perez-Nunez (D) http://orcid.org/0000-0003-02618325

\section{References}

1. "Highly Enriched Uranium: Striking a Balance, A Historical Report on the United States Highly Enriched Uranium Production, Acquisition and Utilization Activities from 1945 Through September 30, 1996," U.S. Department of Energy (2001); http://www.fas.org/sgp/other gov/doe/heu/striking-lofi.pdf (current as of Nov. 11, 2016). 
2. A. TRAVELLI, "Status and Progress of the RERTR Program," presented at 1996 Int. Mtg. Reduced Enrichment for Research and Test Reactors, Seoul, Korea, 1996.

3. M. K. MEYER et al., "Selection and Microstructures of High Density Uranium Alloys," Argonne National Laboratory (1997).

4. P. LEMOINE and D. WACHS, "High Density Fuel Development for Research Reactors," INL/CON-0712889, Idaho National Laboratory (2007).

5. S. van den BERGHE et al., "From High to Low Enriched Uranium Fuel in Research Reactors," Adv. Sci. Technol., 79, 78 (2010); https://www.scientific.net/AST.73.78 (current as of Nov. 11, 2016).

6. Y. S. KIM and G. L. HOFMAN, "Irradiation Behavior of the Interaction Product of U-Mo Fuel Particle Dispersion in an Al Matrix," J. Nucl. Mater, 425, 181 (2012); https://doi. org/10.1016/j.jnucmat.2011.07.032.

7. A. LEENAERS et al., "Post-Irradiation Examination of Uranium-7 wt\% Molybdenum Atomized Dispersion Fuel," J. Nucl. Mater, 335, 39 (2004); https://doi.org/10. 1016/j.jnucmat.2004.07.004.

8. Y. XU and X.-T. YAN, Chemical Vapor Deposition, an Integrated Engineering Design for Advanced Materials, Springer-Verlag, New York (2010).

9. H. O. PIERSON, Handbook of Chemical Vapor Deposition (CVD)_Principles, Technology and Applications, 2nd ed., Elsevier Science (2000).

10. S. KUDAPA et al., "Characterization and Properties of MTCVD TiCN and MTCVD ZrCN Coatings," Surface and Coatings Technol., 120-121, 259 (1999); https://doi. org/10.1016/S0257-8972(99)00484-3.

11. J. REST et al., U-Mo Fuels Handbook, Argonne National Laboratory and Idaho National Laboratory (2006).

12. K.-T. RIE, J. WOHLE, and A. GEBAUER, "Synthesis of Thin Coatings by Plasma-Assisted Chemical Vapour Deposition Using Metallo-Organic Compounds as Precursors," Surf. Coat. Technol., 59, 202 (1993); https:// doi.org/10.1016/0257-8972(93)90083-Z.
13. K. T. RIE and A. GEBAUER, "Plasma-Assisted Chemical Vapour Deposition of Hard Coatings with Metallo-Organic Compounds," Mater. Sci. Eng., A139, 61 (1991); https://doi.org/10.1016/0921-5093 (91)90597-G.

14. Y. PAULEAU, Chemical Physics of Thin Film Deposition Processes for Micro- and Nano- Technologies, Kluwar Academic Publishers, Boston, Massachusetts (2002).

15. I.-W. KIM et al., "Fourier Transform Infrared Spectroscopy Studies on Thermal Decomposition of Tetrakis-DimethylAmido Zirconium for Chemical Vapor Deposition of ZrN," Korean J. Chem. Eng., 21, 1256 (2004); https://doi.org/10. 1007/BF02719504.

16. Material Safety Data Sheet, Tetrakis(Dimethylamino) Zirconium, 99\% TDMAZ, Strem Chemicals, Inc. website; http://www.strem.com (Jan. 2011) (current as of Nov. 11, 2016).

17. H. BERNDT et al., "Zirconium, Carbonitride Films Produced by Plasma-Assisted Metal Organic Chemical Vapour Deposition," Surf. Coat. Technol., 74-75, 369 (1995); https://doi.org/10.1016/0257-8972(95)08242-5.

18. R. FIX, R. G. GORDON, and D. M. HOFFMAN, "Chemical Vapor Deposition of Titanium, Zirconium, and Hafnium Nitride Thin Films," J. Chem. Mater., 3, 1138 (1991); https://doi.org/10.1021/cm00018a034.

19. M. Y. ARRIETA, "Low Temperature Chemical Vapor Deposition of Zirconium Nitride in a Fluidized Bed," MS Thesis, Texas A\&M University (2012).

20. Deep Crust \& Mantle Dynamics Group, Research Facilities: Electron Microprobe Laboratory website; http:// www.dcmd.tamu.edu/research-facilities (current as of Nov. 11, 2016).

21. Q. A. ACTON, Chemical Processes-Advances in Research and Application, p. 300, Scholarly Editions (2012).

22. H. GUILLON and S. BONNAFOUS, "Vaporization of Solid or Liquid Organic, Organometallic or Inorganic Compounds," Gases \& Instrumentation (May 2008). 